\title{
Management of malignant pleural effusions
}

\author{
David Hsia • Ali I. Musani
}

Published online: 7 March 2012

(C) Springer Science+Business Media, LLC 2012

\begin{abstract}
Malignant pleural effusions (MPE) are a common occurrence in many advanced malignancies. They are a significant cause of morbidity and mortality; symptoms can be debilitating to patients and impair quality of life, especially as many of these patients are already functionally impaired by their underlying cancer and medical treatment. MPE generally represent advanced stage malignancy and the primary goal of therapy is palliation of symptoms. The purpose of this article is to review the therapeutic options available in the treatment of MPE and discuss clinical factors affecting management decision-making.
\end{abstract}

Keywords Malignant · Pleural disease - Effusion .

Thoracentesis - Chest tube - Pleural catheter - Thoracoscopy · Pleuroscopy $\cdot$ Pleurodesis $\cdot$ Poudrage

\section{Introduction}

Pleural effusions are a common complication of advanced malignancies and are associated with significant morbidity and mortality. The incidence of MPE is estimated to be greater than 150,000 cases per year in the United States [1, $2]$. Over $75 \%$ of patients with MPE are symptomatic, though a significant number may be asymptomatic with

\section{Hsia $(\triangle)$}

Division of Respiratory

and Critical Care Physiology and Medicine,

Harbor-UCLA Medical Center,

1000 W. Carson Street, Box 405, Torrance, CA 90507, USA

e-mail: dhsia@labiomed.org

\section{A. I. Musani}

National Jewish Health,

1400 Jackson Street, Molly Blank J225,

Denver, CO 80206, USA only evidence of pleural fluid on clinical examination or chest imaging [3]. Common presenting symptoms include dyspnea, cough, orthopnea, and chest pain. Median survival ranges from 3-12 months and depends on the type and stage of the malignancy [4-8].

Treatment for MPE has traditionally included recurrent therapeutic thoracentesis, drainage by chest tube thoracostomy, and pleurodesis. While these modalities remain viable therapeutic options, they are imperfect. Development of new therapies, including long-term indwelling pleural catheters and pleuroscopy, have expanded the spectrum of interventions allowing physicians to offer outpatient [9] and costeffective [10] therapies that decrease hospital stay, decrease discomfort, and allow patients to maximize time at home or in hospice care [11].

\section{Etiology and pathogenesis}

Lung cancer is the most common cause of MPE and is the etiology in more than one-third of cases, followed by cancers of the breast, lymphoma, ovary, and stomach. Combined, these comprise almost $80 \%$ of MPE, though the primary site of origin is unknown in $7 \%$ of cases [12]. These data, however, likely underestimate the role of mesothelioma as a cause of MPE given the increasing incidence of mesothelioma and the higher prevalence of the disease in certain parts of the world [13••]. Most MPE are exudates, though $2 \%-5 \%$ are transudates $[14,15]$.

MPE are diagnosed by the discovery of malignant cells in pleural fluid or pleural biopsy. MPE commonly result from disruption of normal Starling forces regulating pleural fluid absorption by obstruction of mediastinal lymphatics, which drain the pleural space [16]. There is a strong relationship between mediastinal metastasis and development of MPE 
$[3,9,17]$. Other causes of MPE include direct invasion (eg, lung cancer, breast cancer, chest wall neoplasms), hematogenous spread of tumor to the pleura (eg, metastasis, nonHodgkin's lymphoma), or increased capillary permeability caused by tumor invasion-related local inflammatory changes or vascular endothelial growth factor production $[16,18-20]$. Malignancy involving the pleura, however, does not always result in the development of MPE, as MPE are only present in $60 \%$ of such cases $[17,21]$.

Paramalignant effusions develop secondary to tumor effect, such as from thoracic duct obstruction (eg, Hodgkin's lymphoma), bronchial obstruction, pneumonia, atelectasis, trapped lung, pulmonary embolism, or secondary to chemotherapy or radiation treatment [3]. Since pleura is not directly affected, pleural fluid cytology and pleural biopsy are negative for malignant cells.

\section{Therapeutic considerations}

While not all patients with MPE are symptomatic, the majority have symptoms that decrease their quality of life. Dyspnea with exertion affects more than $90 \%$ of symptomatic patients while cough and chest discomfort (ie, pleuritic pain, chest pressure or heaviness) affect over $50 \%$ of patients [22]. In addition to the quantity of pleural fluid, the rate of accumulation is an important factor in the severity of symptoms [3]. As MPE represent advanced disease and portend poor overall prognosis, therapies are considered palliative rather than curative. Systemic chemotherapy can reduce pleural fluid production, though response is heavily dependent upon cancer etiology. Therapeutic options focus on fluid drainage or reduction in fluid production (Table 1). When evaluating therapeutic options, the patient's symptoms, functional status, life expectancy, and underlying etiology of malignancy must be considered (Fig. 1).

\section{Pleural drainage}

Therapeutic thoracentesis

Removal of a large volume of pleural fluid by thoracentesis is generally the first therapeutic intervention tried for patients with symptomatic MPE. Patient response to large volume thoracentesis is also important in determining the future management of their MPE. Up to $50 \%$ of patients may not have significant symptom relief due to comorbid conditions, generalized deconditioning from their malignancy, or incomplete reexpansion of the lung (aka "trapped lung").

Table 1 Treatment options for malignant pleural effusions

\begin{tabular}{|c|c|c|}
\hline Treatment & Advantages & Disadvantages \\
\hline Observation & - Noninvasive & $\begin{array}{l}\text { - Most patients progress and require } \\
\text { therapeutic intervention }\end{array}$ \\
\hline \multirow{3}{*}{$\begin{array}{l}\text { Periodic therapeutic } \\
\text { thoracentesis }\end{array}$} & - Rapid relief of symptoms & - Multiple procedures required \\
\hline & \multirow[t]{2}{*}{$\begin{array}{l}\text { - Good option for patients with limited life } \\
\text { expectancy or slow reaccumulation rate }\end{array}$} & $\begin{array}{l}\text { - Recurrent procedural risk } \\
\text { (ie, pneumothorax) }\end{array}$ \\
\hline & & - Requires periodic medical visits \\
\hline \multirow[t]{5}{*}{ Tunneled pleural catheter } & - Effective control of symptoms & $\begin{array}{l}\text { - Drainage may require assistance from } \\
\text { a caregiver }\end{array}$ \\
\hline & - Allows outpatient management & - Risk of catheter infection \\
\hline & - Minimally invasive & $\begin{array}{l}\text { - Low and slow pleurodesis rate compared to } \\
\text { chemical pleurodesis options }\end{array}$ \\
\hline & \multicolumn{2}{|l|}{ - Possible spontaneous pleurodesis pleurodesis } \\
\hline & \multicolumn{2}{|l|}{$\begin{array}{l}\text { - Can be used with trapped lung or failed } \\
\text { pleurodesis }\end{array}$} \\
\hline \multirow{3}{*}{$\begin{array}{l}\text { Chest tube thoracotomy with } \\
\text { pleurodesis }\end{array}$} & - Permanent relief of symptoms & - 5-7 day hospitalization \\
\hline & \multirow[t]{2}{*}{ - High pleurodesis success rate } & - Invasive \\
\hline & & - Higher associated morbidity \\
\hline \multirow{4}{*}{$\begin{array}{l}\text { Medical thoracoscopy or VATS } \\
\text { with pleurodesis }\end{array}$} & - Permanent relief of symptoms & - 5-7 day hospitalization \\
\hline & - High pleurodesis success rate & - Invasive \\
\hline & \multirow{2}{*}{$\begin{array}{l}\text { Able to perform concurrent } \\
\text { diagnostic and therapeutic } \\
\text { interventions }\end{array}$} & - Higher associated morbidity \\
\hline & & - Must tolerate single-lung ventilation (VATS) \\
\hline \multirow[t]{2}{*}{ Pleuroperitoneal shunt } & - Can be used after failed pleurodesis & - Risk of shunt occlusion \\
\hline & - Recirculation of chyle with chylothorax & - Requires frequent manual pumping \\
\hline
\end{tabular}


Fig. 1 Treatment considerations for malignant pleural effusions

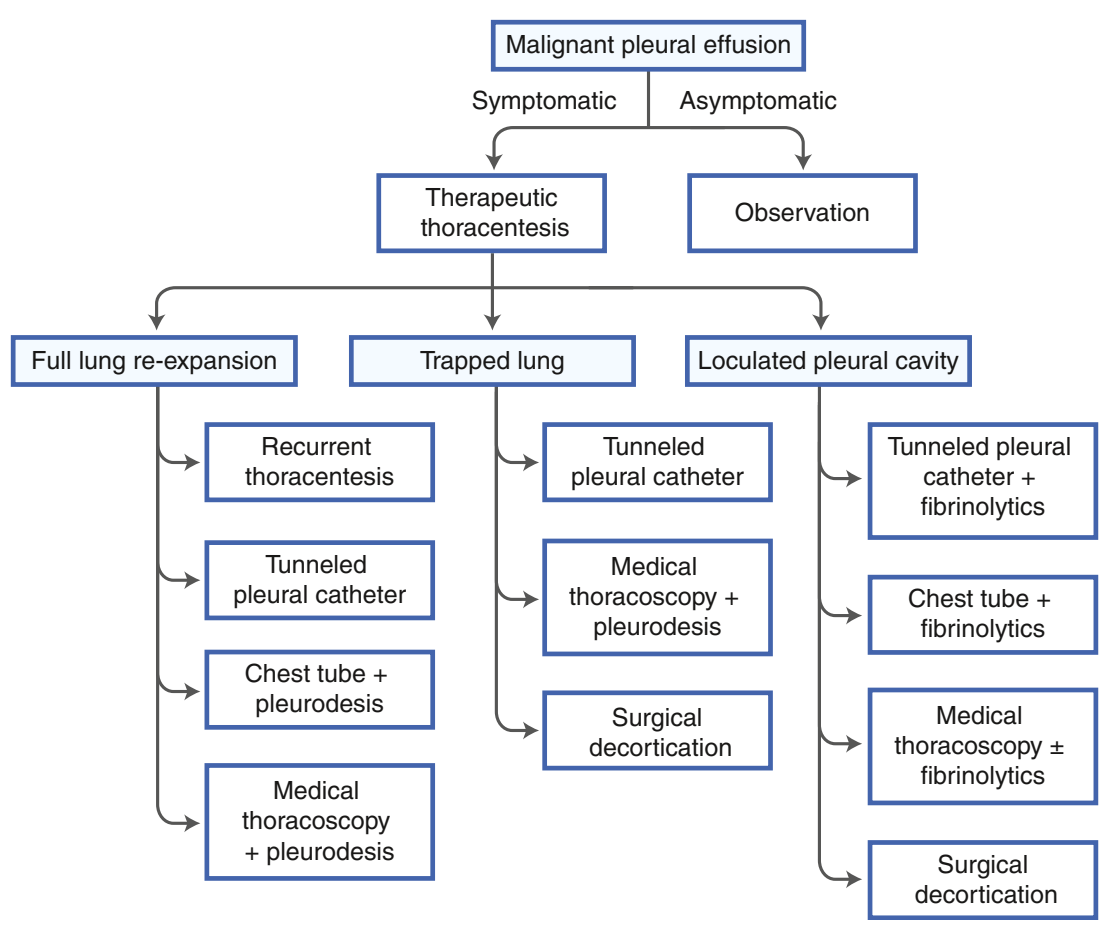

Lack of symptom relief following fluid removal discourages additional, more invasive therapeutic options given the lack of benefit. Trapped lung may result from pleural-based malignancy or metastasis, pleural loculations, or bronchial obstruction with post-obstruction collapse. In addition, radiographic evidence of lung reexpansion and apposition of the parietal and visceral pleura after removal of pleural fluid is an important predictor of success if considering future pleurodesis [23-25].

There are no absolute contraindications to thoracentesis, though relative contraindications include bleeding diathesis, use of anticoagulation, positive pressure ventilation, or minimal effusion size. While the volume of fluid that can safely be removed is unknown, caution must be taken due to the risk of reexpansion pulmonary edema. This is a rare $(<1 \%)$ but well-described complication associated with the rapid reexpansion of the lung [26-28]. Large volume drainage has been shown to be safe if the patient is symptom-free during the procedure and manometry pressures remain less than $-20 \mathrm{~cm} \mathrm{H}_{2} \mathrm{O}$ during the removal of a large quantity of fluid [23]; however, as most clinicians do not routinely measure pleural pressures during thoracentesis, it is recommended not to remove more than $1.5 \mathrm{~L}$ at a time and to avoid use of excessive negative pressure, such as from a vacuum bottle $[13 \cdot \bullet, 29]$.

A total of $98 \%-100 \%$ of patients will have reaccumulation of pleural fluid and recurrence of associated symptoms within 30 days of thoracentesis [30, 31]. Therefore, recurrent thoracentesis may be a viable therapeutic approach for patients who have limited life expectancy or who are poor candidates for more definitive but invasive interventions.
However, the physician should have a candid discussion with the patient regarding procedural-related risks such as infection, bleeding, pneumothorax, and the development of adhesions which may interfere with other therapeutic modalities.

Tunneled pleural catheter

Indwelling tunneled pleural catheters (TPC) have become commonly used for palliative drainage of MPE since its initial approval in 1997 for commercial use by the U.S. Food and Drug Administration. The role of TPC is constantly evolving as it provides physicians a minimally invasive, potentially less expensive, outpatient treatment option.

The most common catheter system in use (PleurX; CareFusion, San Diego, CA, USA) is a $15.5 \mathrm{Fr}$ silicone rubber catheter measuring $66 \mathrm{~cm}$ in length with fenestrations along the distal $24 \mathrm{~cm}$ and a proximal valve. The catheter is tunneled subcutaneously in a procedure akin to a combination of a thoracentesis and modified Seldinger technique $[32,33]$. A polyester cuff along the tunneled portion of the catheter induces fibrotic tissue formation preventing infection and securing the catheter in place. Insertion can be performed under conscious sedation on an outpatient basis in an ambulatory procedure unit. Pleural fluid can be drained via vacuum or drainage bottles by the patient, a family member, or visiting home nurse. The catheter is removable should the patient develop spontaneous pleurodesis or in the event of a complication.

Multiple studies have shown TPC to be effective in drainage of recurrent MPE [9, 10, 34, 35]. A recent meta-analysis 
of 19 studies involving TPC showed symptomatic improvement in $95.6 \%$ of patients and development of spontaneous pleurodesis in $45.6 \%$ (range 11.8-76.4\%) after an average of 52 days [36 ]. Given the non-invasive nature of the therapy, this catheter system has commonly been used in patients with poor prognosis ( $<6$ months) as well as patients who are not optimal candidates for traditional pleurodesis due to a trapped lung or who have failed prior pleurodesis $[37,38 \bullet, 39]$. However, the role of TPC is expanding with the demonstration of utility in patients who otherwise would qualify for traditional pleurodesis [40].

Currently only one study compares TPC to pleurodesis; there was no difference in survival or quality-of-life but a decreased length of hospitalization ( 1.0 vs 6.5 days) when compared to pleurodesis with doxycycline. Costs associated with hospitalization were clearly in favor of TPC use [41]. However, given the high cost associated with the disposable drainage bottles, a recent cost analysis estimated a similar cost between TPC and talc pleurodesis ( $\$ 9011.60$ vs $\$ 8170.80$, respectively) with cost effectiveness favoring the TPC when life expectancy was less than 6 weeks [42•]. Of course, the decision to use a TPC versus pleurodesis should focus on patient preference, comfort, and quality of life rather than cost. TPC-related complications are relatively rare, but include catheter malfunction (9.1\%), dislocation $(2.2 \%)$, obstruction $(3.7 \%)$, and pneumothorax (3.9\%); cellulitis $(3.4 \%)$ and empyema $(2.8 \%)$ have also been reported [9]. Tumor seeding along the catheter tract is rare, but most notable with mesothelioma.

\section{Pleuroperitoneal shunt}

Largely supplanted now by TPC, pleuroperitoneal shunts are used in patients with refractory malignant effusions, failed chemical pleurodesis, trapped lung, or who are not pleurodesis candidates. Pleuroperitoneal shunts transfer fluid from the pleural space to the peritoneal cavity actively when manually pumped (Denver shunt) or passively (LeVeen shunt). Palliation is achieved in $80 \%-90 \%$ of properly selected patients [15]. This method of pleural fluid drainage is particularly useful with chylothorax as it allows recirculation of chyle.

Infection and shunt occlusion are the most significant complications associated with pleuroperitoneal shunts. Shunt occlusion, usually from clotting of the catheter, occurs in up to $25 \%$ of cases with a median length of patency of 2.5 months $[43,44]$.

\section{Pleurodesis}

Pleurodesis eliminates the potential pleural space by inducing inflammation and fibrosis causing the visceral and parietal pleura to adhere together. This process can be incited by the introduction of a chemical sclerosant, by mechanical abrasion of the pleural surface, or by prolonged use of a chest tube. Chemical sclerosants are most commonly introduced through a chest tube, via medical thoracoscopy, or by other surgical intervention. Patients selected for pleurodesis should have significant symptom relief and evidence of full lung reexpansion after removal of pleural fluid. Lung reexpansion is paramount as trapped lung has been associated with chemical pleurodesis failure [45]. The pleurodesis process commonly takes 5-7 days during which time the patient is hospitalized for chest tube drainage and pain control. The chest tube is removed after pleural fluid output diminishes and the patient can then be discharged.

\section{Chest tube thoracostomy}

Chest tube thoracostomy is an inpatient procedure performed under local anesthesia or conscious sedation. Its use in MPE is primarily for drainage of the pleural cavity and demonstration of lung reexpansion before instillation of a chemical sclerosant. Typically a $24-32 \mathrm{Fr}$ chest tube is used, though smaller bore tubes have been used for chemical pleurodesis [46-48]. Large bore chest tubes are associated with greater patient discomfort but have traditionally been used because of the concern of obstruction of smaller bore tubes by fibrin plugs. However, several randomized trials have compared small versus large bore chest tubes without significant difference in pleurodesis outcome [46, 49-51]. Pleurodesis is performed by mixing the sclerosing agent of choice with $50-100 \mathrm{~mL}$ of sterile saline and then instilling it into the pleural cavity through the chest tube. The chest tube is clamped for $1-2 \mathrm{~h}$ and then reconnected to suction. No benefit in distribution of sclerosant or outcome or has been shown from rotating the patient $[52,53]$.

\section{Medical thoracoscopy}

Medical thoracoscopy, also referred to as pleuroscopy, is another diagnostic and therapeutic tool gaining popularity amongst pulmonologists and thoracic surgeons [54, 55•]. The procedure can be performed under local anesthesia with conscious sedation in an endoscopy suite or procedure room. General anesthesia, intubation, and single-lung ventilation are not required. The patient is placed in the lateral decubitus position and one or more trocars are inserted into the pleural space, allowing introduction of the thoracoscope. There are different sizes of trocars (typical diameter $5-13 \mathrm{~mm}$ ) and a variety of thoracoscopes, including semi-rigid versus rigid telescopes in addition to direct $\left(0^{\circ}\right)$, oblique $\left(30\right.$ or $\left.50^{\circ}\right)$, and periscope $\left(90^{\circ}\right)$ visualization options. Visually guided biopsies of parietal pleura, lysis of adhesions (mostly with rigid thoracoscope), and administration of 
chemical sclerosants can be performed before a chest tube is placed through the trocar site at the completion of the procedure.

The procedure requires the patient to tolerate spontaneous breathing under conscious sedation with one lung partially collapsed. Presence of adhesions will influence trocar placement, and adhesiolysis with the telescope or biopsy forceps may be required to allow complete drainage of the pleural cavity and uniform distribution of the sclerosant for pleurodesis. Potential complications include pneumothorax, subcutaneous emphysema, fever, and pain. Reports of major complications such as empyema, sepsis, or death are rare $[56,57]$.

\section{Surgical interventions}

While similar in many ways to medical thoracoscopy, videoassisted thoracic surgery (VATS) has several distinct and clinically important differences. The equipment is similar in concept to rigid medical thoracoscopes, though usually slightly larger in size. VATS permits a greater number of diagnostic and therapeutic options compared to medical thoracoscopy, such as diagnostic biopsy of lung parenchyma and select hilar lymph nodes. However, it requires a higher level of surgical expertise and is performed in an operating room, which requires greater ancillary and logistical support. VATS also requires at least two trocars, general anesthesia, and single-lung ventilation through a double-lumen endotracheal tube. Despite its increased complexity, it remains a valuable tool in the evaluation and pleurodesis of the pleural cavity.

Thoracotomy and decortication can be used for the treatment of MPE with loculations and/or trapped lung. It has a significantly higher associated mortality rate and is generally reserved for the limited population of patients with significant symptoms, prolonged life expectancy, and who have failed other therapeutic interventions. Variations of pleurectomy (radical pleurectomy and decortication, lung-sparing total pleurectomy, and extrapleural pneumonectomy) have been used to treat malignant mesothelioma. While successful at achieving pleurodesis, these surgical interventions are associated with a high morbidity and mortality; as such, their use in malignant mesothelioma is now discouraged $[58,59 \bullet]$.

Pleurodesis agents and administration

The ideal sclerosing agent is chosen based on factors such as efficacy, accessibility, ease of administration, and safety profile. A number of chemical sclerosants have been utilized in pleurodesis, including talc, bleomycin, tetracycline, doxycycline, iodoprovidone, and mustine. Talc is now generally accepted as the agent of choice $[13 \bullet \bullet, 60]$; meta- analysis suggests successful pleurodesis is more likely with talc compared to other agents or chest tube drainage alone (RR 1.34, CI 1.16-1.55) [61]. Success rates with talc are reported to be $81 \%-93 \%$ [62-65], as compared to $80 \%-$ $85 \%$ with tetracycline/doxycycline [66-68] and 70\%-79\% with bleomycin [64, 69].

Chemical sclerosing agents can be administered either through a chest tube (slurry) or insufflated into the pleural cavity during medical thoracoscopy or VATS (poudrage). Several studies have demonstrated similar or better pleurodesis rates with talc poudrage compared to talc slurry, though these data are not completely conclusive [70-73]. The largest of these trials randomized 501 patients to talc poudrage versus talc slurry with 30 -day pleurodesis rates of $78 \%$ versus $71 \%$, respectively [70]. However, subgroup analysis showed increased success with talc poudrage $(82 \%$ versus $67 \%$ ) in patients with lung or breast cancers compared to other primary malignancies. Despite this controversy, medical thoracoscopy or VATS-administered talc poudrage has specific situational advantages over talc slurry. Diagnostic biopsy and therapeutic pleurodesis can be performed simultaneously; in addition, procedural removal of adhesions and direct visualization permits confirmation of adequate drainage of the pleural cavity and widespread dispersal of the sclerosing agent.

Other factors have been shown to be associated with pleurodesis outcomes. Low pleural fluid $\mathrm{pH}$ has been shown to be a poor prognostic indicator for pleurodesis success with receiver operating curve thresholds for $\mathrm{pH}$ of 7.28 $7.34[74,75]$. Other predictors of poor pleurodesis results include trapped lung [45], large tumor bulk lining the pleural surfaces [76], and elevated adenosine deaminase levels [75]. Predictors of successful pleurodesis include pleural fluid output of $<200 \mathrm{~mL} /$ day when treated by talc slurry [77] as well as MPE secondary to lung adenocarcinomas that are positive for epidermal growth factor receptor (EGFR) mutation when treated with Tarceva [78].

The most common complications associated with chemical pleurodesis are fever and pain [11]. Other potential complications include local site infection, empyema, arrhythmias, cardiac arrest, myocardial infarction, and hypotension. Doxycycline is commonly associated with more pleuritic pain than talc. Acute respiratory distress syndrome (ARDS), acute pneumonitis, and respiratory failure have been described with use of talc. ARDS has been described in up to $1 \%-9 \%$ of cases of talc pleurodesis [79], though recent investigation has shown that this may be related to the use of ungraded talc as opposed to large particle talc $(>15 \mu \mathrm{m})$. Janssen and colleagues prospectively treated 558 patients using large particle talc without a single occurrence of ARDS, demonstrating that use of graded large particle talc is preferable [79]. 


\section{Intrapleural fibrinolytics}

Fibrinolytics instilled into the pleural cavity have been used for treatment of non-malignant loculated effusions, such as with parapneumonic effusions and empyema. Fibrin deposits along the pleura in MPE can lead to loculations hindering pleurodesis and resulting in dyspnea and trapped lung. Streptokinase [80] and urokinase [81] have been used with loculated MPE with an increase in pleural fluid output and improvement in dyspnea. The only prospective randomized control trial used streptokinase and a $10 \mathrm{Fr}$ drainage tube in patients with MPE; this resulted in increased pleural fluid drainage, increased number of patients with lung reexpansion ( $96 \%$ vs $74 \%)$, and increased success with doxycycline pleurodesis ( $74 \%$ vs $56 \%$ ) [82].

\section{Future directions}

\section{Multimodality interventions}

The ultimate goal of therapeutic intervention for MPE is to provide rapid onset of symptom relief with minimally invasive interventions and minimal hospital length-of-stay. To this end, Reddy and colleagues recently evaluated patients with recurrent, symptomatic MPE who underwent medical thoracoscopy with talc poudrage; the chest tube was removed after $24 \mathrm{~h}$ and drainage was continued via TPC [83]. Patients were potentially discharged if stable after the chest tube was discontinued. Using this multimodality approach, pleurodesis was successfully achieved in $92 \%$ of patients and the TPC was removed at a mean of 16.7 days. Mean length of hospitalization was only 3.2 days post procedure. While only a pilot study, combination therapy has the potential to provide permanent symptom relief while minimizing hospital length-of-stay.

\section{Subcutaneous implantable pleural port}

Recently, Kriegel and colleagues described their experience using an $8.5 \mathrm{Fr}$ fenestrated pleural catheter attached to an implantable access port (Celsite ST, Laboratoires Braun, France) [84]. The access port is positioned in a subcutaneous compartment created along the mid-axillary line over the 10th to 12th ribs with the catheter inserted between the third to fifth intercostals space and directed towards the lung base via fluoroscopic guidance. The procedure can be performed as an outpatient and allows access of the port with a Huber needle and drainage bottle to remove pleural fluid.

One hundred and sixty-eight devices were implanted in 137 patients. Ninety-eight percent had complete or partial relief of their dyspnea, and $36.8 \%$ developed spontaneous pleurodesis within 2 months. Median patient survival time was 344 days. Complications included infection (1 empyema, 2 cellulitis) and 3 mechanical complications. Catheter occlusion was also described which was resolved with instillation of urokinase. Though additional studies using this device are required, the potential advantage over a TPC is that the external catheter and valve are implanted subcutaneously, similar to implanted ports used for chronic infusion therapy (eg, Portacath, Infusaport). Such devices have the potential to decrease infection risk and improve patient comfort and aesthetics.

\section{Intrapleural chemotherapy}

Administration of chemotherapeutic agents directly into the pleural space has the potential to control the underlying malignancy and/or the MPE by producing high drug concentrations localized at the malignancy site while minimizing systemic toxicity [85]. Ideal agents would have a slow clearance rate from the intrapleural cavity, allowing greater exposure of cancer cells to the cytotoxic agent. In addition, ideal agents have limited tissue penetration to decrease systemic absorption; however, the utility of intrapleural chemotherapy may therefore be limited in patients with bulky disease. A phase II trial of intrapleural paclitaxel demonstrated a 370-fold increase in intrapleural versus serum drug levels [86]. Chemotherapeutics studied include paclitaxel, cisplatin, carboplatin, etoposide, cytarabine, and docetaxel [85, 87-91]; unique agents such as Staphylococcus aureus superantigen have also been tried [92]. The majority of studies to date are phase I and II trials evaluating safety and dosing rather than efficacy. A phase III trial using intrapleural cisplatin versus observation noted a decrease in significant MPE development in non-small cell lung cancer patients with cytologically positive pleural fluid ( $8 \%$ vs $42 \%, P=0.008$ ) [90]; however, the trial was stopped early due to poor enrollment. Given current indwelling methods allowing chronic access to the pleural cavity, intrapleural chemotherapy remains a potential mechanism of drug administration, though further studies are needed.

\section{Conclusions}

There are a number of palliative treatment options available for patients with MPE. Pleurodesis offers the potential for permanent relief of symptoms for patients able to tolerate the procedure. Newer modalities, such as TPC, can provide less invasive yet long-term solutions for patients with poor functional status and still has the potential for eventual pleurodesis. TPC also offers palliation for patients with trapped lung who are unable to undergo pleurodesis. Ultimately a multitude of factors must be considered when evaluating patients with MPE, including functional status, 
symptoms, and overall prognosis in order to choose the most efficacious, cost-effective, and minimally invasive means to meet the patient's goals of care.

Acknowledgment None of the authors received financial support or assistance for this project.

Disclosure D. Hsia: none; A. I. Musani: consultancy, honoraria, and speakers' bureaus for CareFusion.

\section{References}

Papers of particular interest, published recently, have been highlighted as:

- Of importance

•. Of major importance

1. Neragi-Miandoab S. Malignant pleural effusion, current and evolving approaches for its diagnosis and management. Lung Cancer. 2006;54:1-9.

2. American Thoracic Society. Management of malignant pleural effusions. Am J Respir Crit Care Med. 2000;162:1987-2001.

3. Chernow B, Sahn SA. Carcinomatous involvement of the pleura: an analysis of 96 patients. Am J Med. 1977;63:695-702.

4. Abbruzzese JL, Abbruzzese MC, Hess KR, et al. Unknown primary carcinoma: natural history and prognostic factors in 657 consecutive patients. J Clin Oncol. 1994;12:1272-80.

5. van de Molengraft FJ, Vooijs GP. Survival of patients with malignancy-associated effusions. Acta Cytol. 1989;33:911-6.

6. Sears D, Hajdu SI. The cytologic diagnosis of malignant neoplasms in pleural and peritoneal effusions. Acta Cytol. 1987;31:8597.

7. Bonnefoi H, Smith IE. How should cancer presenting as a malignant pleural effusion be managed? Br J Cancer. 1996;74:832-5.

8. Kolschmann S, Ballin A, Gillissen A. Clinical efficacy and safety of thoracoscopic talc pleurodesis in malignant pleural effusions. Chest. 2005; 128:1431-5.

9. Musani AI, Haas AR, Seijo L, et al. Outpatient management of malignant pleural effusions with small-bore, tunneled pleural catheters. Respiration. 2004;71:559-66.

10. Putnam Jr JB, Walsh GL, Swisher SG, et al. Outpatient management of malignant pleural effusion by a chronic indwelling pleural catheter. Ann Thorac Surg. 2000;69:369-75.

11. Musani AI. Treatment options for malignant pleural effusion. Curr Opin Pulm Med. 2009;15:380-7.

12. Sahn SA. Pleural diseases related to metastatic malignancies. Eur Respir J. 1997;10:1907-13.

13. •• Roberts ME, Neville E, Berrisford RG, et al. Management of a malignant pleural effusion: British Thoracic Society pleural disease guideline 2010. British Thoracic Society guidelines on the management of malignant pleural effusions. Provides review of data and graded strength of recommendations.

14. Porcel JM, Alvarez M, Salud A, et al. Should a cytologic study be ordered in transudative pleural effusions? Chest. 1999;116:18367.

15. Ashchi M, Golish J, Eng P, et al. Transudative malignant pleural effusions: prevalence and mechanisms. South Med J. 1998;91:236.

16. Khaleeq G, Musani AI. Emerging paradigms in the management of malignant pleural effusions. Respir Med. 2008;102:939-48.
17. Meyer PC. Metastatic carcinoma of the pleura. Thorax. 1966;21:437-43.

18. Das DK. Serous effusions in malignant lymphomas: a review. Diagn Cytopathol. 2006;34:335-47.

19. Yano S, Shinohara H, Herbst RS, et al. Production of experimental malignant pleural effusions is dependent on invasion of the pleura and expression of vascular endothelial growth factor/vascular permeability factor by human lung cancer cells. Am J Pathol. 2000;157:1893-903.

20. Yano S, Herbst RS, Shinohara H, et al. Treatment for malignant pleural effusion of human lung adenocarcinoma by inhibition of vascular endothelial growth factor receptor tyrosine kinase phosphorylation. Clin Cancer Res. 2000;6:957-65.

21. Light RW, Hamm H. Malignant pleural effusion: would the real cause please stand up? Eur Respir J. 1997;10:1701-2.

22. Martinez-Moragon E, Aparicio J, Sanchis J, et al. Malignant pleural effusion: prognostic factors for survival and response to chemical pleurodesis in a series of 120 cases. Respiration. 1998;65:10813.

23. Hausheer FH, Yarbro JW. Diagnosis and treatment of malignant pleural effusion. Semin Oncol. 1985;12:54-75.

24. Adler RH, Sayek I. Treatment of malignant pleural effusion: a method using tube thoracosctomy and talc. Ann Thorac Surg. 1976;22:8-15.

25. Villanueva AG, Gray Jr AW, Shahian DM, et al. Efficacy of short term versus long term tube thoracostomy drainage before tetracycline pleurodesis in the treatment of malignant pleural effusions. Thorax. 1994;49:23-5.

26. Feller-Kopman D, Berkowitz D, Boiselle P, et al. Large-volume thoracentesis and the risk of reexpansion pulmonary edema. Ann Thorac Surg. 2007;84:1656-61.

27. Mahfood S, Hix WR, Aaron BL, et al. Reexpansion pulmonary edema. Ann Thorac Surg. 1988;45:340-5.

28. Tarver RD, Broderick LS, Conces Jr DJ. Reexpansion pulmonary edema. J Thorac Imaging. 1996;11:198-209.

29. Antony VB, Loddenkemper R, Astoul P, et al. Management of malignant pleural effusions. Eur Respir J. 2001;18:402-19.

30. Sorenson PG, Svendsen TL, Enk B. Treatment of malignant pleural effusion with drainage, with and without instillation of talc. Eur J Respir Dis. 1984;65:131-5.

31. Groth G, Gatzemeier U, Haussingen $\mathrm{K}$, et al. Intrapleural palliative treatment of malignant pleural effusions with mitoxantrone versus placebo (pleural tube alone). Ann Oncol. 1991;2:2135 .

32. Stather DR, Tremblay A. Use of tunneled pleural catheters for outpatient treatment of malignant pleural effusions. Curr Opin Pulmon Med. 2007;13:328-33.

33. MacEachern P, Stather DR, Tremblay A. Tunneled pleural catheters. In: Beamis JFJ, Mathur P, Mehta A, editors. Interventional pulmonary medicine. New York: Informa Healthcare; 2009.

34. Van den Toorn LM, Schaap E, Surmont VF, et al. Management of recurrent malignant pleural effusions with a chronic indwelling pleural catheter. Lung Cancer. 2005;50:123-7.

35. Tremblay A, Michaud G. Single-center experience with 250 tunnelled pleural catheter insertions for malignant pleural effusion. Chest. 2006;129:362-8.

36. • Van Meter ME, McKee KY, Kohlwes RJ. Efficacy and safety of tunneled pleural catheters in adults with malignant pleural effusions: a systematic review. J Gen Intern Med. 2011;26:70-76. Meta-analysis of 19 studies investigating tunneled pleural catheters.

37. Qureshi RA, Collinson SL, Powell RJ, et al. Management of malignant pleural effusion associated with trapped lung syndrome. Asian Cardiovasc Thorac Ann. 2008;16:120-3.

38. • Efthymiou CA, Masudi T, Thorpe JA, et al. Malignant pleural effusion in the presence of trapped lung. Five-year experience of PleurX tunneled catheters. Interact Cardiovasc Thorac Surg. 
2009;9:961-964. Description of treatment of trapped lung by tunneled pleural catheter drainage.

39. Sioris T, Sihvo E, Salo J, et al. Long-term indwelling pleural catheter (PleurX) for malignant pleural effusion unsuitable for talc pleurodesis. Eur J Surg Oncol. 2009;35:546-51.

40. Tremblay A, Mason C, Michaud G. Use of tunneled catheters for malignant pleural effusions in patients fit for pleurodesis. Eur Respir J. 2007;30:759-62.

41. Putnam Jr JB, Light RW, Rodriguez RM, et al. A randomized comparison of indwelling pleural catheter and doxycycline pleurodesis in the management of malignant pleural effusions. Cancer. 1999;86:1992-9.

42. - Olden AM, Holloway R. Treatment of malignant pleural effusion: PleuRx catheter or talc pleurodesis? A cost-effectiveness analysis. J Palliat Med. 2010;13:59-65. Cost-benefit analysis of tunneled pleural catheter versus pleurodesis treatment modalities.

43. Reich H, Beattie EJ, Harvey JC. Pleuroperitoneal shunt for malignant pleural effusions: a one-year experience. Semin Surg Oncol. 1993;9:160-2.

44. Lee KA, Harvey JC, Reich H, et al. Management of malignant pleural effusions with pleuroperitoneal shunting. J Am Coll Surg. 1994;178:586-8.

45. Kennedy L, Rusch VW, Strange C, et al. Pleurodesis using talc slurry. Chest. 1994;106:342-6.

46. Clementsen P, Evald T, Grode G, et al. Treatment of malignant pleural effusion: pleurodesis using a small percutaneous catheter. A prospective randomized study. Respir Med. 1998;92:593-6.

47. Goff BA, Mueller PR, Muntz HG, et al. Small chest-tube drainage followed by bleomycin sclerosis for malignant pleural effusions. Obstet Gynecol. 1993;81:993-6.

48. Chen YM, Shih JF, Yang KY, et al. Usefulness of pig-tail catheter for palliative drainage of malignant pleural effusions in cancer patients. Support Care Canc. 2000;8:423-6.

49. Spiegler PA, Hurewitz AN, Groth ML. Rapid pleurodesis for malignant pleural effusions. Chest. 2003;23:1895-8.

50. Parulekar W, Di Primio G, Matzinger F, et al. Use of small-bore vs. large-bore hest tubes for treatment of malignant pleural effusions. Chest. 2001;120:19-25.

51. Caglayan B, Torun E, Turan D, et al. Efficacy of iodopovidone pleurodesis and comparison of small-bore catheter versus large bore chest tube. Ann Surg Oncol. 2008;15:2594-9.

52. Dryzer SR, Allen ML, Strange C, et al. A comparison of rotation and nonrotation in tetracycline pleurodesis. Chest. 1993;104:17639.

53. Mager HJ, Maesen B, Verzijlbergen F, et al. Distribution of talc suspension during treatment of malignant pleural effusion with talc pleurodesis. Lung Cancer. 2002;36:77-81.

54. Tassi GF, Davies RJO, Noppen M. Advanced techniques in medical thoracoscopy. Eur Respir J. 2006;28:1051-9.

55. - Lee P, Mathur PN, Colt HG. Advances in Thoracoscopy: 100 years since Jacobaeus. Respiration. 2010;79:177-186. Review detailing the equipment, procedure, and considerations involved with medical thoracoscopy.

56. Menzies R, Charbonneau M. Thoracoscopy for the diagnosis of pleural disease. Ann Intern Med. 1991;114:271-6.

57. Colt HG. Thoracoscopy. A prospective study of safety and outcome. Chest. 1995;108:324-9.

58. Zahid I, Sharif S, Routledge T, et al. Is pleurectomy and decortication superior to palliative care in the treatment of malignant pleural mesothelioma? Interact Cardiovasc Thorac Surg. 2011;12:812-7.

59. • Treasure T, Lang-Lazdunski L, Waller D, et al. Extra-pleural pneumonectomy versus no extra-pleural pneumonectomy for patients with malignant pleural mesothelioma: clinical outcomes of the Mesothelioma and Radical Surgery (MARS) randomised feasibility study. Lancet Oncol. 2011;12:763-772. Large trial investigating the use of pneumonectomy in the treatment of mesothelioma.

60. Tan C, Sedrakyan A, Browne J, et al. The evidence on the effectiveness of management for malignant pleural effusion: a systematic review. Eur J Cardiothor Surg. 2006;29:829-38.

61. Shaw P, Agarwal R. Pleurodesis for malignant pleural effusions. Cochrane Database Syst Rev. 2004; (1):CD002916.

62. Ferrer J, Montes JF, Villarino MA, et al. Influence of particle size on extrapleural talc dissemination after talc slurry pleurodesis. Chest. 2002;122:1018-27.

63. Paschoalini MDS, Vargas FS. Marchi et al. Prospective randomized trial of silver nitrate vs. talc slurry in pleurodesis for symptomatic malignant pleural effusions. Chest. 2005;128:684-9.

64. Zimmer PW, Hill M, Casey K, et al. Prospective randomized trial of talc slurry vs bleomycin for symptomatic malignant pleural effusions. Chest. 1997;112:430-4.

65. Walker-Renard P, Vaughan LM, Sahn SA. Chemical pleurodesis for malignant pleural effusions. Ann Intern Med. 1994;120:56-64.

66. Patz EF, McAdams HP, Erasmus JJ, et al. Sclerotherapy for malignant pleural effusions: a prospective randomized trial of bleomycin vs doxycycline with small-bore catheter drainage. Chest. 1998;113:1305-11.

67. Heffner JE, Standerfer RJ, Torstveit J, et al. Clinical efficacy of doxycycline for pleurodesis. Chest. 1994;105:1743-7.

68. Pulsiripunya C, Youngchaiyud P, Puspakorn R, et al. The efficacy of doxycycline as a pleural sclerosing agent in malignant pleural effusion: a prospective study. Respirology. 1996;1:69-72.

69. Ong $\mathrm{KC}$, Indumathi $\mathrm{V}$, Raghuram $\mathrm{J}$, et al. A comparative study of pleurodesis using talc slurry and bleomycin in the management of malignant pleural effusions. Respirology. 2000;5:99-103.

70. Dresler CM, Olak J, Herndon 2nd JE, et al. Phase 3 intergroup study of talc poudrage vs talc slurry sclerosis for malignant pleural effusion. Chest. 2005;127:909-15.

71. Manes N, Rodriguez-Panadero F, Bravo J, et al. Talc pleurodesis. Prospective and randomized study clinical follow up. Chest. 2000;118:131S.

72. Stefani A, Natali P, Casali C, et al. Talc poudrage versus talc slurry in the treatment of malignant pleural effusion. A prospective comparative study. Eur J Cardiothorac Surg. 2006;30:827-32.

73. Yim AP, Chan AT, Lee TW, et al. Thoracoscopic talc insufflations versus talc slurry for symptomatic malignant pleural effusion. Ann Thorac Surg. 1996;62:1655-8.

74. Heffner JE, Nietert PJ, Barbieri C. Pleural fluid $\mathrm{pH}$ as a predictor of pleurodesis failure: analysis of primary data. Chest. 2000;117:87-95.

75. Yildirim H, Metintas M, Guntulu Ak, et al. Predictors of talc pleurodesis outcome in patients with malignant pleural effusions. Lung Cancer. 2008;62:139-44.

76. Sahn SA. Pleurodesis for malignant and nonmalignant pleural effusions. Clin Pulm Med. 1999;6:141-6.

77. Aydogmus U, Ozdemir S, Cansever L, et al. Bedside talc pleurodesis for malignant pleural effusion: factors affecting success. Ann Surg Oncol. 2009;16:745-50.

78. Guo H, Wan Y, Tian G, et al. EGFR mutations predict a favorable outcome for malignant pleural efusión of lung adenocarcinoma with Tarceva therapy. Oncol Rep. 2011; [epub ahead of print on November 23, 2011]

79. Janssen JP, Collier G, Astoul P, et al. Safety of pleurodesis with talc poudrage in malignant pleural effusion: a prospective cohort study. Lancet. 2007;369:1535-9.

80. Davies CW, Traill ZC, Gleeson FV, et al. Intrapleural streptokinase in the management of malignant multiloculated pleural effusions. Chest. 1999;115:729-33.

81. Hsu LH, Soong TC, Feng AC, et al. Intrapleural urokinase for the treatment of loculated malignant pleural effusiosn and trapped 
lungs in medically inoperable cancer patients. J Thorac Oncol. 2006;1:460-7.

82. Okur E, Baysungur V, Tezel C, et al. Asian Cardiovasc Thorac Ann. 2011;19:238-43.

83. Reddy C, Ernst A, Lamb C, et al. Rapid pleurodesis for malignant pleural effusions. Chest. 2011;139:1419-23.

84. Kriegel I, Daniel C, Falcou MC, et al. Use of a subcutaneous implantable pleural port in the management of recurrent malignant pleurisy: five-year experience based on 168 subcutaneous implantable pleural ports. J Palliat Med. 2011;14:829-34.

85. Perng RP, Chen YM, Wu MF, et al. Phase II trial of intrapleural paclitaxel injection for non-small-cell lung cancer patients with malignant pleural effusions. Respir Med. 1998;92:473-9.

86. Lombardi G, Nicoletto MO, Gusella M, et al. Intrapleural paclitaxel for malignant pleural effusion from ovarian and breast cancer: a phase II study with pharmacokinetic analysis. Cancer Chemother Pharmacol. Epub ahead of print 2011, Oct 29.

87. Lerza R, Vannozzi MO, Tolino G, et al. Carboplatin and cisplatin pharmacokinetics after intrapleural combination treatment in patients with malignant pleural effusion. Ann Oncol. 1997;385391.
88. Thoda Y, Iwanaga T, Takada M, et al. Intrapleural administration of cisplatin and etoposide to treat malignant pleural effusions in patients with non-small cell lung cancer. Chemotherapy. 1999;45:197-204.

89. Shoji T, Tanaka F, Yanagihara K, et al. Phase II study of repeated intrapleural chemotherapy using implantable access system for management of malignant pleural effusion. Chest. 2002;121:8214.

90. Ichinose Y, Tsuchiya R, Koike T. A prematurely terminated phase III trial of intraoperative intrapleural hypotonic cisplatin treatment in patients with resected non-small cell lung cancer with positive pleural lavage cytology: the incidence of carcinomatous pleuritis after surgical intervention. J Thorac Cardiovasc Surg. 2002;123:6959.

91. Jones DR, Taylor MD, Petroni GR, et al. Phase I trial of intrapleural docetaxel through an implantable catheter in subjects with a malignant pleural effusion. J Thorac Oncol. 2010;5:75-81.

92. Ren S, Terman DS, Bohach G, et al. Intrapleural staphylococcal superantigen induces resolution of malignant pleural effusions and a survival benefit in non-small cell lung cancer. Chest. 2004;126:1529 39. 